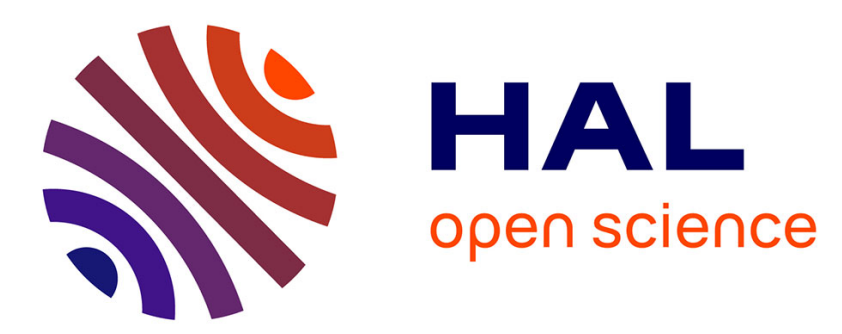

\title{
Genetic diversity and associated pathology of isolated from porcine pneumonia
}

\author{
S.E. Pors, M.S. Hansen, H. Christensen, H.E. Jensen, A. Petersen, M. \\ Bisgaard
}

\section{> To cite this version:}

S.E. Pors, M.S. Hansen, H. Christensen, H.E. Jensen, A. Petersen, et al.. Genetic diversity and associated pathology of isolated from porcine pneumonia. Veterinary Microbiology, 2011, 150 (3-4), pp.354. 10.1016/j.vetmic.2011.02.050 . hal-00696625

\section{HAL Id: hal-00696625 \\ https://hal.science/hal-00696625}

Submitted on 13 May 2012

HAL is a multi-disciplinary open access archive for the deposit and dissemination of scientific research documents, whether they are published or not. The documents may come from teaching and research institutions in France or abroad, or from public or private research centers.
L'archive ouverte pluridisciplinaire HAL, est destinée au dépôt et à la diffusion de documents scientifiques de niveau recherche, publiés ou non, émanant des établissements d'enseignement et de recherche français ou étrangers, des laboratoires publics ou privés. 


\section{Accepted Manuscript}

Title: Genetic diversity and associated pathology of Pasteurella multocida isolated from porcine pneumonia

Authors: S.E. Pors, M.S. Hansen, H. Christensen, H.E. Jensen, A. Petersen, M. Bisgaard

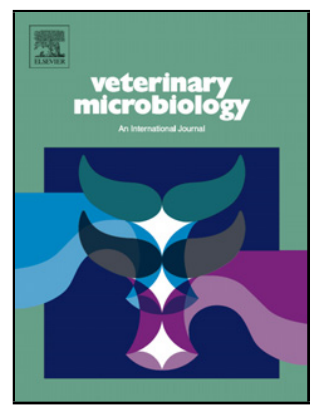

PII: S0378-1135(11)00132-5

DOI: doi:10.1016/j.vetmic.2011.02.050

Reference: VETMIC 5217

To appear in: VETMIC

Received date: 18-3-2009

Revised date: 21-2-2011

Accepted date: 24-2-2011

Please cite this article as: Pors, S.E., Hansen, M.S., Christensen, H., Jensen, H.E., Petersen, A., Bisgaard, M., Genetic diversity and associated pathology of Pasteurella multocida isolated from porcine pneumonia, Veterinary Microbiology (2010), doi:10.1016/j.vetmic.2011.02.050

This is a PDF file of an unedited manuscript that has been accepted for publication. As a service to our customers we are providing this early version of the manuscript. The manuscript will undergo copyediting, typesetting, and review of the resulting proof before it is published in its final form. Please note that during the production process errors may be discovered which could affect the content, and all legal disclaimers that apply to the journal pertain. 


\section{Genetic diversity and associated pathology of Pasteurella multocida isolated}

2 from porcine pneumonia

4 S.E. Pors, M.S. Hansen, H. Christensen, H E. Jensen, A. Petersen and M. Bisgaard

5 Department of Veterinary Disease Biology, Faculty of Life Sciences, University of Copenhagen,

6 Frederiksberg, Denmark.

Corresponding author: S.E. Pors, Department of Veterinary Disease Biology, Faculty of Life

9 Sciences, University of Copenhagen, Ridebanevej 3, DK-1870 Frederiksberg C, Denmark. Phone:

10 +45 3533 3763. Fax: +45 35353514. E-mail: sup@life.ku.dk

12 Abstract

13 Pasteurella multocida is a widespread respiratory pathogen in pigs associated with atrophic rhinitis 14 and contributing to aggravation of the pulmonary lesions. The aims of the present study were to 15 characterize isolates of $P$. multocida from porcine bronchopneumonia by pulsed-field gel 16 electrophoresis (PFGE), PCR based capsular typing and multilocus sequence typing (MLST) and to compare clonal complexes outlined with the type of histological lung lesions to investigate if a correlation between clonal lineages and lesions might exist. Isolates of $P$. multocida were obtained

19 from cases of cranioventrally located porcine bronchopneumonia. All lung lesions were described and classified according to histological lesions. A total of 139 isolates, from lung $(\mathrm{n}=111)$,

21 pericardial sac $(\mathrm{n}=21)$ and kidney $(\mathrm{n}=7)$ of 111 pigs were described using PFGE with ApaI as the restriction enzyme. Furthermore, 20 and 29 isolates were characterized by capsular serotyping and multilocus sequence typing, respectively. PFGE demonstrated 15 different clusters showing $50 \%$ or more similarity. All selected isolates were of capsular serotype A and only three main sequence 
types (ST) were detected among the isolates. Associations were not found between histopathology and clonal complexes of $P$. multocida. In conclusion, PFGE demonstrated a high diversity of genotypes of $P$. multocida associated with porcine bronchopneumonia. However, isolates obtained mainly belonged to few STs, indicating that isolates of $P$. multocida associated with porcine bronchopneumonia originates from a limited number of clonal lineages and therefore might have adapted to porcine hosts. No correlation was demonstrated between genotypes and types of lesions, and extra-pulmonary spreading was only rarely demonstrated.

\section{Keywords: Porcine bronchopneumonia, Pasteurella multocida, pulsed-field gel electrophoresis,} multilocus sequence typing

\section{Introduction}

Infectious bronchopneumonia is a widespread and well-known disease of pigs used for meat production (Sørensen et al., 2006). In a Danish study, bronchopneumonia was demonstrated in $25 \%$ of the pigs at slaughter (Christensen and Enoe, 1999). Similar reports have been published from other countries (Gois et al., 1975; Osborne et al., 1981; von Altrock, 1998; Maes et al., 2001). Both viruses and bacteria have been included in the aetiology of porcine pneumonia (Thacker, 2001; Sørensen et al., 2006; Hansen et al., 2010). Among these, the Gram-negative bacterium Pasteurella multocida, associated with a broad disease spectrum in animals (Hunt et al., 2000), constitutes a frequent finding (Gois et al., 1975; Morrison et al., 1985; Falk et al., 1991; von Altrock, 1998; Ross, 2006), and it is suggested that P. multocida may play a central role in the porcine respiratory disease complex (PRDC) (Thacker, 2001; Pijoan, 2006; Ross, 2006; Sørensen et al., 2006; Hansen et al., 2010). Compared to bronchopneumonia and atrophic rhinitis, systemic infections with $P$. multocida in pigs are infrequently reported, although acute septicaemia due to capsular serotypes B 
and D has been reported from Asia and Australia (Mackie et al., 1992; Cameron et al., 1996; Pijoan, 2006). Finally, P. multocida has been associated with the porcine dermatitis and nephropathy syndrome (PDNS), a disease of unknown aetiology recognized in many pig-producing countries (Thomson et al., 2001; Lainson et al., 2002). A variety of lesions in porcine lungs have been associated with $P$. multocida, including mild exudative as well as extensive necrotizing lesions and abscess formation (Pijoan, 2006; Hansen et al., 2010). Factors influencing the outcome, however, remain to be elucidated. In addition, only little is known about the host response to invasion in the lungs, just as possible systemic spreading remains to be confirmed. The difference observed in pathological manifestations might be explained as a result of differences in virulence of the bacteria previously reported for avian isolates of $P$. multocida (Pedersen et al., 2003; Eigaard et al., 2006). Although strains of $P$. multocida obtained from porcine bronchopneumonia have been typed and characterized using several different approaches, such correlations between isolates and pathology have not been reported for porcine isolates (Zucker et al., 1996; Fussing et al., 1999; Bowles et al., 2000; Lainson et al., 2002; Moreno et al., 2003; Jamaludin et al., 2005). However, demonstration of a small number of $P$. multocida variants associated with the majority of cases of porcine pneumonia in the United Kingdom during a twelve year period might suggest that strains associated with lung lesions represent primary pathogens rather than secondary invaders (Davies et al., 2003). Pulsedfield gel electrophoresis (PFGE) has previously been used to investigate the genetic diversity of $P$. multocida (Aalbaek et al., 1999; Lainson et al., 2002; Pedersen et al., 2003). However, results obtained have not been compared with the type of lesions found in bronchopneumonia. For this reason the aims of the present study were to characterize isolates of $P$. multocida from porcine bronchopneumonia by capsular typing, PFGE and multilocus sequence typing (MLST) and to compare clonal complexes outlined with the type of lesions found in the lungs and to examine if a correlation between clonal lineages and lesions might exist. In addition, isolates from the lungs, 
pericardial sac and kidney of the same animal were compared in order to investigate if isolates from the pericardial sac and kidney were identical with those obtained from the lung.

\section{Materials and Methods}

\subsection{Cases of bronchopneumonia and bacterial isolates}

Cases of cranioventrally located porcine bronchopneumonia with positive cultivation of $P$. multocida, randomly collected at two Danish slaughter houses during 2006, were included in the present study (Hansen et al., 2010). The animals originated from 80 separate farms. In addition to isolates from the lung, isolates of $P$. multocida from the pericardial sac and kidney of pigs demonstrating bronchopneumonia with isolation of $P$. multocida, were included. All organs were cultured using sterile cotton swabs after heat decontamination of the surface. The swabs were plated on blood agar (Blood agar Base CM 55, Oxoid, Basingstoke, United Kingdom, added 5\% bovine blood) and incubated at $37^{\circ} \mathrm{C}$ in a sealed plastic bag for $24 \mathrm{~h}$. Isolates showing typical colony morphology of $P$. multocida were sub-cultured and identified using procedures as previously reported by Hansen et al. (2010). Growth of $P$. multocida on the primary plates and gross lesions were evaluated as previously reported (Hansen et al., 2010). Evaluation of histopathology was done according to Hansen et al. (2010) and Pors et al. (2011) leading to the following groups of histopathology: acute, subacute, chronic necrotizing, chronic suppurative, chronic mixed and chronic non-suppurative bronchopneumonia.

\subsection{Pulsed-field gel electrophoresis}

Isolates of $P$. multocida were kept at $-80^{\circ} \mathrm{C}$ in brain heart infusion (BHI) broth (Difco, Heidelberg, Germany) with $10 \%$ glycerol (LIFE Pharmacy, Copenhagen, Denmark) and were plated on blood agar. Inoculated plates were incubated at $37^{\circ} \mathrm{C}$ in sealed plastic bags for $18-24$ hours. From pure 
cultures, a single colony typical of $P$. multocida was grown overnight in $10 \mathrm{ml} \mathrm{BHI}$ (Difco) at $37^{\circ} \mathrm{C}$ with shaking. The optical density at $578 \mathrm{~nm}$ was measured using $200 \mu \mathrm{l}$ of bacterial suspension added to $800 \mu$ l SE-buffer (75mM NaCl (Merck, Darmstadt, Germany), 25mM EDTA (Merck) [pH 7.4]). Approximately $3 \mathrm{ml}$ of culture was used for DNA preparation. The culture was centrifuged at $10,000 \mathrm{rpm}$ for $25 \mathrm{~min}$ after which the supernatant was discarded and the pellet re-suspended in 4.5 ml SE-buffer followed by centrifugation. After discarding the supernatant and adding SE-buffer as adjustment for density, the suspension of bacterial DNA was mixed with an equal amount of $1 \%$ low-melting-point agarose (Seakem GTG agarose, FMC Bioproducts) and dispensed into a plug mould. After solidification the blocks were digested overnight at $56^{\circ} \mathrm{C}$ in ES-buffer $(1 \% \mathrm{~N}$ lauroylsarcosin (Sigma-Aldrich, Steinheim, Germany), 0.5M EDTA (Merck) [pH 9.5]) added Proteinase K $(0.5 \mathrm{mg} / \mathrm{ml})$ (Roche, Basel, Switzerland). The blocks were then washed in cold $\left(4^{\circ} \mathrm{C}\right)$ TE-buffer. Subsequently, the purified DNA was washed in restriction buffer (NEBuffer 4, B7003S, New England BioLabs, Massachusetts, USA) containing $10 \mathrm{mg} / \mathrm{ml}$ bovine serum albumin (B9001S, New England BioLabs) and digested overnight with $2 \mu \mathrm{l}$ ApaI (R0114, New England BioLabs) at $25^{\circ} \mathrm{C}$ as this has previously been used in PFGE analysis of $P$. multocida isolates (Lainson et al., 2002). The fragments were separated in a 1\% agarose gel (Pulsed Field Certified Agarose, BioRad, Richmond, California) in 0.5×TB-buffer (Tris/boric acid (Merck), 0.5 M EDTA (Merck) [pH 8.]) using a CHEF-DR III system (Bio-Rad) at $14^{\circ} \mathrm{C}$ for $20 \mathrm{hr}$. The electrophoresis conditions were: an initial switch time of $1 \mathrm{sec}$, a final switch time of $15 \mathrm{sec}$, a potential difference of $5.6 \mathrm{~V} / \mathrm{cm}$ and an included angle of $120^{\circ} \mathrm{C}$. Gel images were analyzed and banding profiles compared using GelCompar II (Applied Maths, Belgium). Subsequently, the Unweighted Pair Group Method with Arithmetic Average (UPGMA) was used for cluster analyses using the DICE similarity coefficient and a band-matching index greater than $0.8 \%$ among the profiles. To determine clonality among the isolates, guidelines presented by Lainson et al. (2002) and Tenover et al. (1995) were used. 


\subsection{Capsular PCR}

123 Twenty isolates obtained from lung lesions, were randomly selected to represent major clusters

124 according to PFGE. A multiplex capsular PCR based upon capsule-specific primer pairs (CAPA, 125 CAPB, CAPD, CAPE, and CAPF) was used as described by Townsend et al. (2001).

Twenty-nine isolates were selected randomly to represent major clusters based upon PFGE. MLST was performed according to Subaaharan et al. (2010). Seven housekeeping gene fragments adk

129 (coding for adenylate kinase), est (esterase), pmi (mannose-6-phosphate isomerase), zwf (glucose-6130 phosphate-1-dehydrogenase), $m d h$ (malate dehydrogenase), $g d h$ (glutamate dehydrogenase) and $p g i$ 131 (glucose-6-phosphate-isomerase) were characterized. PCR conditions included an initial 132 denaturation of $5 \mathrm{~min}$ at $94^{\circ} \mathrm{C} ; 30$ cycles of $\left(94^{\circ} \mathrm{C}, 30 \mathrm{~s} ; 48^{\circ} \mathrm{C}, 30 \mathrm{~s} ; 72^{\circ} \mathrm{C}, 1 \mathrm{~min}\right)$ and a final 133 elongation at $72^{\circ} \mathrm{C}$ for $5 \mathrm{~min}$. For the $g d h$ gene the annealing temperature was $58^{\circ} \mathrm{C}$ instead of $13448^{\circ} \mathrm{C}$. Residual dNTPs and primers were removed by mixing $10 \mu \mathrm{l}$ PCR-mixture with $1 \mu 1$ 135 exonuclease I and $2 \mu \mathrm{l}$ calf intestine alkaline phosphatase (Fermentas, St. Leon-Rot, Germany). The 136 samples were incubated for $15 \mathrm{~min}$ at $37^{\circ} \mathrm{C}$ and subsequently at $85^{\circ} \mathrm{C}$ to stop the enzymatic 137 reaction. Sequencing was performed at Macrogen Inc., Seoul, Korea, using the PCR primers. 138 Sequencing results were analyzed with Vector NTI 10.1.1 (Invitrogen, Carlsbad, USA) and 139 assembled sequences aligned and compared using ClustalW at www.ebi.ac.uk. Using the

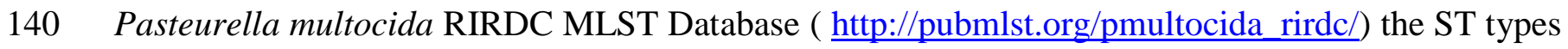
141 found was compared to previous findings. 
144 Association between PFGE and lesion types demonstrated was done by Fisher's exact test. 145 Significance level was set to $\mathrm{P}<0.05$. All analysis was done using SAS version 9.1 (SAS Institute, 146 Cary, NC, USA). For statistical analysis, histopathological observations were pooled according to 147 the age of lesion (acute, subacute, chronic) to ensure adequate group sizes. Furthermore, analyses 148 were performed among the groups of lungs with chronic lesions (necrotizing, suppurative, mixed, 149 non-suppurative). Clusters with a number of isolates below ten were not included in the statistical 150 analyses.

\section{Results}

\subsection{Bacteriology}

154 A total of 111 isolates of $P$. multocida were obtained from the lungs of cases of cranioventral located bronchopneumonia Of these 96 were demonstrated in pure culture, while colonies of $P$. multocida present in a mixed culture were obtained in 15 cases. Massive growth (more than 300 colonies) were found in 76 cases, dense growth (25-300 colonies) in 21 cases and weak growth ( $<25$ colonies) in 14 cases. Isolates of P. multocida were also obtained from the kidney in 7 animals. All isolates from the kidney were in pure culture, massive growth was found in 4 cases and dense growth were found in 3 cases. Isolates obtained from the pericardial sac were kept and included for further examination in 21 out of 40 cases with positive cultivation of $P$. multocida from the pericardial sac. Of these 19 were demonstrated in pure culture, while colonies of $P$. multocida present in a mixed culture were obtained in 2 cases. Massive growth (more than 300 colonies) were

164 found in 4 cases, dense growth (25-300 colonies) in 6 cases and weak growth ( $<25$ colonies) in 11 cases. Four of the cases had simultaneous isolation of $P$. multocida from kidney and pericardial sac. Isolates from lung, pericardial sac and kidney all shared the same colony morphology, typical of $P$. multocida. 


\subsection{Pathology}

170 Lung lesions from which $P$. multocida was cultivated and included for further characterization 171 ( $\mathrm{n}=111)$ were grouped into six categories according to histopathology (Table 2). There were only 172 eight acute and 21 subacute cases of bronchopneumonia. The most frequent finding was chronic 173 bronchopneumonia $(n=82)$ represented by different types of exudation in alveoli, including neutrophils or a mixed cell population consisting of lymphocytes, macrophages and neutrophils. Additionally, multifocal necrotic lesions were found in a single subacute case and in eight cases of the chronic bronchopneumonia. A detailed description of the histopathological findings has been 177 reported by Hansen et al. (2010).

\subsection{PFGE analysis}

A total of 139 isolates of $P$. multocida obtained from lung $(\mathrm{n}=111)$, pericardial $\mathrm{sac}(\mathrm{n}=21)$ and kidney ( $\mathrm{n}=7$ ) were examined by PFGE. The PFGE patterns obtained with ApaI as the restriction enzyme included 7-13 clear and well separated bands. A total of 15 clusters (A-O) demonstrated more than 50\% similarity (Table 1 and Fig. 1). Clusters A and B each contained 34 isolates. Within these clusters accumulations of clonally related isolates representing several farms were observed. two (I and J) clusters contained four, three and two isolates, respectively. Five clusters (K, L, M, N and $\mathrm{O}$ ) only included a single isolate each. A total of 47 isolates formed 13 clusters (Fig. 1) each of which demonstrated $90 \%$ or more similarity. The similarity of PFGE profiles of isolates obtained from lung, pericardial sac and/or kidney is shown in Table 2. In nine out of 24 animals isolates 
191 different with the exception of isolates from three animals from which two out of three isolates 192 demonstrated an identical profile.

\subsection{Association between PFGE clusters, pathology and cultivation of P. multocida}

195 The nine isolates obtained from necrotic lung lesions belonged to 7 different clusters (Table 1 ) and 196 a significant association between PFGE clusters and necrosis was not observed $(\mathrm{P}=0.12)$. 197 Furthermore, an association between the clusters outlined and groups of histopathology (acute, 198 subacute, chronic) $(\mathrm{P}=0.49)$ or groups of chronic cases (necrotizing, suppurative, mixed, non199 suppurative) $(\mathrm{P}=0.32)$ was not demonstrated. Neither was a significant association between the 200 clusters outlined and isolation of $P$. multocida from the pericardial sac and/or kidney found $201(\mathrm{P}=0.40)$. Using the definition of clonal relationship between isolates defined by Tenover et al. 202 (1995) did not demonstrate clones that correlated with groups of histological lesions either $203(\mathrm{P}=0.15)$ (data not shown).

\subsection{Capsular typing}

206 All isolates selected randomely to represent major PFGE clusters for capsular PCR belonged to 207 capsular serotype A.

\subsection{MLST}

210 Three groups of sequence types (STs) were demonstrated (Table 3). The largest group made up the 211 clonal complex 13 and comprised ST13 (21 isolates) or ST149 (one isolate). Four isolates belonged 212 to clonal complex 74 including ST74 (3 isolates) or ST148 (one isolate), while the last group 213 comprised three isolates belonging to clonal complex 50 (ST50, ST150 and ST146). Within the 214 three clonal complexes, the STs share 6 out of seven alleles. ST50 and ST74 differ in five out of 
seven alleles and ST13 demonstrates seven unique alleles compared to ST50 and ST74 (Table 3).

All three clonal complexes have been reported in the Pasteurella multocida RIRDC MLST

217 Database to be mainly associated with pigs in a worldwide distribution. Due to the uneven distribution of STs among the 29 sampled animals, a statistical analysis of a possible correlation with histopathology was not possible.

\section{Discussion}

A high prevalence of $P$. multocida is usually demonstrated from cases of porcine bronchopneumonia (Gois et al., 1975; Morrison et al., 1985; Falk et al., 1991; Hansen et al., 2010). However, strains of $P$. multocida associated with bronchopneumonia in pigs are usually considered secondary pathogens being dependent on co-infections or immunosuppression of the host (Pijoan, 2006; Ross, 2006). The present study characterized isolates from naturally occurring porcine bronchopneumonia to investigate the genetic diversity of the isolates and to investigate a possible link between genotypes and the histopathology of the corresponding lung lesions. In addition, isolates found in the kidney and pericardial sac was compared with lung isolates from the same 230 animal, to investigate the possibility of systemic spreading of the infection. The results showed that 231 P. multocida isolated from bronchopneumonia in pigs demonstrate a high genetic diversity. Based upon PFGE a total of 15 clusters demonstrating 50\% similarity or more were outlined. Using the same cut of value Lainson et al. (2002) only demonstrated four clusters among 51 isolates. A high genetic variation among isolates from porcine pneumonia has also been reported by others, although other methods were used and based on a small number of isolates compared to this study (Djordjevic et al., 1998). Application of restrictrion endonuclease analyses (REA) and ribotyping, has demonstrated less genetic diversity among isolates from porcine pneumonia (Zhao et al., 1992; 
239 affected pigs were randomly selected and represent isolates which are not epidemiologically connected.

Demonstrations of a low number of STs and a few clonal complexes of P. multocida, however, seems to indicate that only a limited number of clones seem to be associated with porcine bronchopneumonia in Danish pig herds. The three major STs demonstrated in this study, ST13, ST50 and ST74 and the subtypes (146-150) hereof, all belong to $P$. multocida subspecies multocida (unpublished data). These STs have previously also mainly been reported associated with pigs (http://pubmlst.org/pmultocida_rirdc/) indicating an adaptation to this host. MLST results also demonstrate that several evolutionary lines of $P$. multocida independently may have adapted to the porcine host since the sequence types differ in most of the alleles. These observations confirm previous findings by Davies et al. (2003), who showed that the majority of isolates of $P$. multocida from porcine pneumonia only made up four different outer-membrane protein (OMP) types.

Previous studies have used different molecular methods to describe the genetic diversity of $P$. multocida obtained from porcine pneumonia (Pijoan et al., 1983; Zhao et al., 1992; Zucker et al., 1996; Blackall et al., 2000; Rubies et al., 2002). However, none of these studies examined the possible association between the genotypes and histopathological findings in the lung. In the present study a connection between PFGE clusters of $P$. multocida and histopathological findings was not demonstrated, indicating the important role of other infectious agents and/or management factors in the outcome of porcine bronchopneumonia (Sørensen et al., 2006; Hansen et al., 2010). With an uneven distribution of the STs among the 29 sampled animals it was not possible to carry out any meaningful statistical analyses of the association between ST and histopathological findings. 
ST50 and ST13 did not occur in animals with chronic suppurative lesions (data not shown). This observation should be further investigated in future studies.

All isolates of $P$. multocida selected for capsular serotyping, were found to be of capsular type A in agreement with previous studies (Pijoan et al., 1983; Zhao et al., 1992; Djordjevic et al., 1998; Davies et al., 2003). In contrast, strains found in porcine atrophic rhinitis often belong to capsular serotype D (Sakano et al., 1992; Gardner et al., 1994; Davies et al., 2003), indicating that isolates of P. multocida associated with atrophic rhinitis and bronchopneumonia, respectively, seem to represent different clonal lineages. Investigations of the tonsillary flora of apparently normal pigs demonstrated a high prevalence of capsular serotype A (Townsend et al., 2000; Jamaludin et al., 2005) and typing these strains might give insight as to whether the clones found in this study originate from the tonsils. Comparison of isolates from lung and extra-pulmonary sites, including the kidney and pericardial sac, showed the same PFGE profile in only nine out of 24 animals. Previous studies of paired isolates from lung and kidney demonstrated similar results for eight out of 14 animals based on REA (Buttenschon and Rosendal, 1990). Lainson et al. (2002) demonstrated identical PFGE profiles of isolates of $P$. multocida, obtained from different isolation sites, including kidney and lung, in pigs suffering from PDNS. These results indicate that a spreading of infection might be possible. However, it could be speculated whether the discrepancies observed might be due to contamination, infection with multiple clones or clearance of the bacteria in chronic cases. A majority of the histopathological findings in the lungs was characterized as chronic and therefore it could be speculated whether a systemic spread was cleared by the host at the time of examination, thereby leading to the low isolation rate of bacteria from the kidney. As P. multocida is reported as a zoonotic organism (Bisgaard et al., 1994; Iaria and Cascio, 2007), systemic spreading of the 
organism in pigs used for human consumption might represent a potential source of human infection. Consequently the risks and rate of the spreading should be further examined.

In conclusion, the results of the present study clearly demonstrated the presence of highly diverse genotypes of $P$. multocida in porcine bronchopneumonia. However, isolates obtained mainly 291 belonged to a few STs, indicating that isolates of $P$. multocida associated with porcine bronchopneumonia originates from a limited number of clonal lineages which and therefore might have adapted to porcine hosts. No relation was demonstrated between genotypes outlined and type of lesion, and extra-pulmonary spreading was only rarely demonstrated.

\section{Acknowledgments}

The authors would like to acknowledge Betina Andersen, Lisbeth Kioerboe, Hanne H. Moeller, Tony Bønnelycke and Katrine Madsen for excellent technical assistance.

\section{References}

Aalbaek, B., Eriksen, L., Rimler, R.B., Leifsson, P.S., Basse, A., Christiansen, T., Eriksen, E., 1999. Typing of Pasteurella multocida from haemorrhagic septicaemia in Danish fallow deer

Bisgaard, M., Frederiksen, W., Mannheim, W., Mutters, R., 1994. Zoonoses caused by organisms classifed with Pasteurellaceae. In: Beran, G.W. (Ed.), Handbook of Zoonoses. Section A. Bacteria, Rickettsial, Chlamydial and Mycotic. CRC press, London, pp. 203-208. 
309 Blackall, P.J., Fegan, N., Pahoff, J.L., Storie, G.J., McIntosh, G.B., Cameron, R.D., O'Boyle, D., 310 Frost, A.J., Bara, M.R., Marr, G., Holder, J., 2000. The molecular epidemiology of four outbreaks 311 of porcine pasteurellosis. Vet. Microbiol. 72, 111-120.

312 Bowles, R.E., Pahoff, J.L., Smith, B.N., Blackall, P.J., 2000. Ribotype diversity of porcine 313 Pasteurella multocida from Australia. Aust. Vet. J. 78, 630-635.

314 Buttenschon, J., Rosendal, S., 1990. Phenotypical and genotypical characteristics of paired isolates 315 of Pasteurella multocida from the lungs and kidneys of slaughtered pigs. Vet. Microbiol. 25, 67-75.

316 Cameron, R.D., O'Boyle, D., Frost, A.J., Gordon, A.N., Fegan, N., 1996. An outbreak of 317 haemorrhagic septicaemia associated with Pasteurella multocida subsp gallicida in large pig herd. 318 Aust. Vet. J. 73, 27-29.

319 Christensen, G., Enoe, C., 1999. [The prevalence of pneumonia, pleuritis, pericarditis and liver 320 spots in Danish slaugther pigs in 1998, including comparation with 1994]. Dansk Veterinærtidskrift $32182,1-12$

322 Davies, R.L., MacCorquodale, R., Baillie, S., Caffrey, B., 2003. Characterization and comparison of 323 Pasteurella multocida strains associated with porcine pneumonia and atrophic rhinitis. J. Med.

324 Microbiol. 52, 59-67.

325 Djordjevic, S.P., Eamens, G.J., Ha, H., Walker, M.J., Chin, J.C., 1998. Demonstration that 326 Australian Pasteurella multocida isolates from sporadic outbreaks of porcine pneumonia are non327 toxigenic (toxA-) and display heterogeneous DNA restriction endonuclease profiles compared with 328 toxigenic isolates from herds with progressive atrophic rhinitis. J. Med. Microbiol. 47, 679-688. 
329 Eigaard, N.M., Permin, A., Christensen, J.P., Bojesen, A.M., Bisgaard, M., 2006. Clonal stability of 330 Pasteurella multocida in free-range layers affected by fowl cholera. Avian Pathol. 35, 165-172.

331 Falk, K., Hoie, S., Lium, B.M., 1991. An abattoir survey of pneumonia and pleuritis in slaughter 332 weight swine from 9 selected herds. II. Enzootic pneumonia of pigs: microbiological findings and 333 their relationship to pathomorphology. Acta Vet. Scand. 32, 67-77.

334 Fussing, V., Nielsen, J.P., Bisgaard, M., Meyling, A., 1999. Development of a typing system for 335 epidemiological studies of porcine toxin-producing Pasteurella multocida ssp. multocida in 336 Denmark. Vet. Microbiol. 65, 61-74.

337 Gardner, I.A., Kasten, R., Eamens, G.J., Snipes, K.P., Anderson, R.J., 1994. Molecular 338 fingerprinting of Pasteurella multocida associated with progressive atrophic rhinitis in swine herds. 339 J. Vet. Diagn. Invest 6, 442-447.

340 Gois, M., Sisak, F., Kuksa, F., Sovadina, M., 1975. Incidence and evaluation of the microbial flora 341 in the lungs of pigs with enzootic pneumonia. Zentralbl. Veterinarmed. B 22, 205-219.

342 Hansen,M.S., Pors,S.E., Jensen,H.E., Hansen,V.B., Bisgaard,M., Flachs,E.M. \& Nielsen,O.L. 2010. 343 An investigation of the pathology and pathogens associated with porcine respiratory disease 344 complex in Denmark. J Comp Pathol., 143, 120-131

345 Hunt, M.L., Adler, B., Townsend, K.M., 2000. The molecular biology of Pasteurella multocida. 346 Vet. Microbiol. 72, 3-25. 
348 Jamaludin, R., Blackall, P.J., Hansen, M.F., Humphrey, S., Styles, M., 2005. Phenotypic and 349 genotypic characterisation of Pasteurella multocida isolated from pigs at slaughter in New Zealand. $350 \quad$ N. Z. Vet. J. 53, 203-207.

351 Lainson, F.A., Aitchison, K.D., Donachie, W., Thomson, J.R., 2002. Typing of Pasteurella 352 multocida isolated from pigs with and without porcine dermatitis and nephropathy syndrome. J. 353 Clin. Microbiol. 40, 588-593. Mackie, J.T., Barton, M., Kettlewell, J., 1992. Pasteurella multocida septicaemia in pigs. Aust. Vet. 355 J. 69, 227-228. Maes, D.G., Deluyker, H., Verdonck, M., Castryck, F., Miry, C., Vrijens, B., Ducatelle, R., De, K.A., 2001. Non-infectious factors associated with macroscopic and microscopic lung lesions in slaughter pigs from farrow-to-finish herds. Vet. Rec. 148, 41-46.

Moreno, A.M., Baccaro, M.R., Ferreira, A.J., Pestana De Castro, A.F., 2003. Use of single-enzyme 360 amplified fragment length polymorphism for typing Pasteurella multocida subsp. multocida isolates 361 from pigs. J. Clin. Microbiol. 41, 1743-1746.

362 Morrison, R.B., Pijoan, C., Hilley, H.D., Rapp, V., 1985. Microorganisms associated with 363 pneumonia in slaughter weight swine. Can. J. Comp Med. 49, 129-137.

364 Osborne, A.D., Saunders, J.R., Sebunya, T., 1981. An abattoir survey of the incidence of 365 pneumonia in Saskatchewan swine and an investigation of the microbiology of affected lungs. Can. 366 Vet. J. 22, 82-85. 
367 Pedersen, K., Dietz, H.H., Jorgensen, J.C., Christensen, T.K., Bregnballe, T., Andersen, T.H., 2003. 368 Pasteurella multocida from outbreaks of avian cholera in wild and captive birds in Denmark. J.

369 Wildl. Dis. 39, 808-816.

370 Pijoan, C., 2006. Pneumonic pasteurellosis. In: Straw B., et.al (Eds.), Diseases in Swine. Iowa 371 State University Press, Ames, IA, pp. 719-726.

372 Pijoan, C., Morrison, R.B., Hilley, H.D., 1983. Serotyping of Pasteurella multocida isolated from 373 swine lungs collected at slaughter. J. Clin. Microbiol. 17, 1074-1076.

374 Pors, S.E., Hansen, M.S., Bisgaard, M., Jensen, H.E., 2011. Occurrence and associated lesions of 375 Pasteurella multocida in porcine bronchopneumonia. Vet. Microbiol. In Press.

376 Ross, R.F., 2006. Pasteurella multocida and its role in porcine pneumonia. Anim Health Res. Rev. $377 \quad 7,13-29$.

378 Rubies, X., Casal, J., Pijoan, C., 2002. Plasmid and restriction endonuclease patterns in Pasteurella 379 multocida isolated from a swine pyramid. Vet. Microbiol. 84, 69-78.

380 Sakano, T., Taneda, A., Okada, M., Ono, M., Hayashi, Y., Sato, S., 1992. Toxigenic type A

381 Pasteurella multocida as a causative agent of nasal turbinate atrophy in swine. J. Vet. Med. Sci. 54, $382 \quad 403-407$.

383 Subaaharan, S.,Blackall L.L., Blackall P.J. 2010. Development of a multi-locus sequence typing 384 scheme for avian isolates of Pasteurella multocida. Vet. Microbiol. 141, 354-361.

385 Sørensen, V., Jorsal, S.E., Mousing, J., 2006. Diseases of the Respiratory System. In: Straw, B.E., 386 Zimmerman, J.J., D'Allaire, S., Taylor, D.J. (Eds.), Diseases of Swine. Blackwell, pp. 149-178. 
387 Tenover, F.C., Arbeit, R.D., Goering, R.V., Mickelsen, P.A., Murray, B.E., Persing, D.H., 388 Swaminathan, B., 1995. Interpreting chromosomal DNA restriction patterns produced by pulsed389 field gel electrophoresis: criteria for bacterial strain typing. J. Clin. Microbiol. 33, 2233-2239.

390 Thacker, E.L., 2001. Immunology of the porcine respiratory disease complex. Vet. Clin. North Am. 391 Food Anim Pract. 17, 551-565.

392 Thomson, J.R., MacIntyre, N., Henderson, L.E., Meikle, C.S., 2001. Detection of Pasteurella 393 multocida in pigs with porcine dermatitis and nephropathy syndrome. Vet. Rec. 149, 412-417.

394 Townsend, K.M., Boyce, J.D., Chung, J.Y., Frost, A.J., Adler, B., 2001. Genetic organization of 395 Pasteurella multocida cap Loci and development of a multiplex capsular PCR typing system. J. 396 Clin. Microbiol. 39, 924-929.

397 Townsend, K.M., Hanh, T.X., O'Boyle, D., Wilkie, I., Phan, T.T., Wijewardana, T.G., Trung, N.T., 398 Frost, A.J., 2000. PCR detection and analysis of Pasteurella multocida from the tonsils of 399 slaughtered pigs in Vietnam. Vet. Microbiol. 72, 69-78.

400 von Altrock, A., 1998. [Occurrence of bacterial infectious agents in pathologically/anatomically 401 altered lungs of pigs and compilation of resistance spectra]. Berl Munch. Tierarztl. Wochenschr. $402111,164-172$.

403 Zhao, G., Pijoan, C., Murtaugh, M.P., Molitor, T.W., 1992. Use of restriction endonuclease analysis 404 and ribotyping to study epidemiology of Pasteurella multocida in closed swine herds. Infect.

405 Immun. 60, 1401-1405. 
406 Zucker, B., Kruger, M., Horsch, F., 1996. Differentiation of Pasteurella multocida subspecies

407 multocida isolates from the respiratory system of pigs by using polymerase chain reaction 408 fingerprinting technique. Zentralbl. Veterinarmed. B 43, 585-591. 
Table 1. Isolates of P. multocida characterized by PFGE. Distribution according to herd, isolation from kidney and/or pericardial sac and type of bronchopneumonia for clusters demonstrating more than 50\% similarity by PFGE analysis.

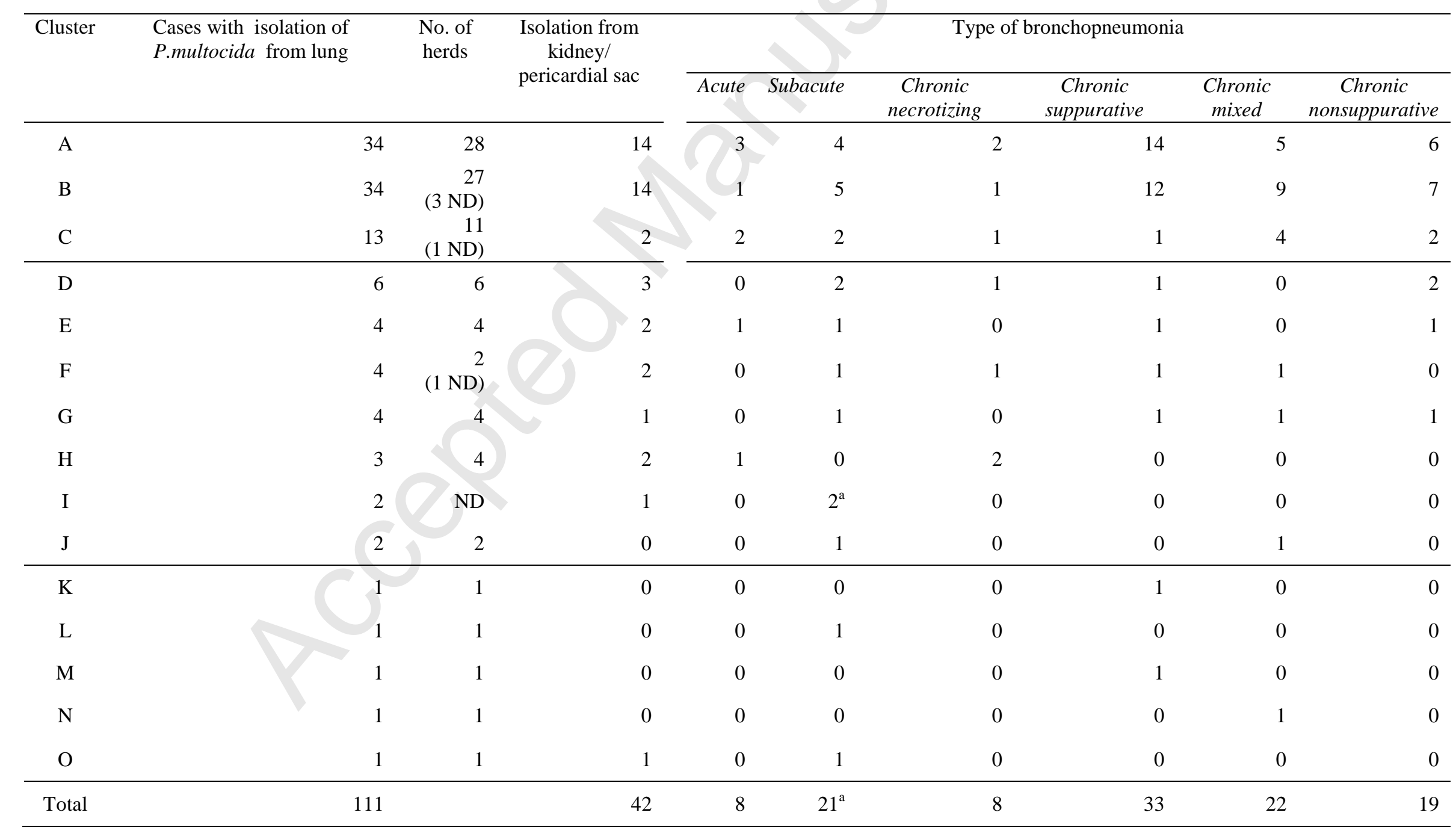

ND: herd origin not reported. a: One case of necrotizing pneumonia 
Table 2. Clonality of PFGE profiles between isolates from different organs in the same pig.

Similarity of PFGE profiles of isolates of P. multocida obtained from lung, pericardial sac and/or kidney from the same pig. Clonality of profiles were defined as $90 \%$ or higher similarity

\begin{tabular}{|c|c|c|c|}
\hline \multirow{2}{*}{$\begin{array}{l}\text { Organ with } \\
\text { positive } \\
\text { culture of } P \text {. } \\
\text { multocida }\end{array}$} & \multicolumn{3}{|c|}{ PFGE profile } \\
\hline & $\begin{array}{l}\text { PFGE } \\
\text { cluster }\end{array}$ & $\begin{array}{c}\text { No. of animals } \\
\text { with clonal isolates obtained } \\
\text { from different organs }\end{array}$ & $\begin{array}{c}\text { No. of animals } \\
\text { with unrelated isolates } \\
\text { obtained from different organs }\end{array}$ \\
\hline Lung & $\mathrm{A}$ & 2 & 4 \\
\hline Pericardial & B & 4 & 3 \\
\hline $\mathrm{sac}$ & $\mathrm{D}$ & - & 1 \\
\hline 17 animals & $\mathrm{E}$ & & 2 \\
\hline & G & & - \\
\hline Lung & B & & 1 \\
\hline $\begin{array}{l}\text { Kidney } \\
3 \text { animals }\end{array}$ & I & & 1 \\
\hline Lung & $\mathrm{B}$ & & $\overline{1^{2}}$ \\
\hline Kidney & $\mathrm{D}$ & & $2^{b, c}$ \\
\hline Pericardial & & & \\
\hline 4 animals & & & \\
\hline
\end{tabular}

a: Isolates from kidney and lung were identical.

b: Isolates from kidney and heart were identical.

c: Isolates of lung and heart were identical. 
Table 3. Clonal complex, sequence type (ST) and allelic profile demonstrated among 29 isolates of P. multocida randomly selected to represent the genetic diversity outlined by PFGE.

\begin{tabular}{|c|c|c|c|c|c|c|c|c|c|}
\hline \multirow{2}{*}{$\begin{array}{l}\text { Clonal } \\
\text { complex }\end{array}$} & \multirow{2}{*}{$\begin{array}{l}\text { Sequence } \\
\text { type }\end{array}$} & \multicolumn{7}{|c|}{ Gene and allelic profile } & \multirow{2}{*}{$\begin{array}{l}\text { Clusters represented } \\
\text { (isolates with ST /total } \\
\text { isolates typed from cluster) }\end{array}$} \\
\hline & & $a d k$ & est & pmi & $z w f$ & $m d h$ & $g d h$ & $p g i$ & \\
\hline \multirow[t]{4}{*}{13} & 13 & 7 & 11 & 9 & 10 & 4 & 7 & 8 & $\mathrm{~A}(4 / 6) \mathrm{B}(6 / 7) \mathrm{C}(2 / 3) \mathrm{D}(1 / 2)$ \\
\hline & & & & & & & & & $\mathrm{E}(1 / 1) \mathrm{F}(1 / 1) \mathrm{G}(1 / 1) \mathrm{J}(1 / 1)$ \\
\hline & & & & & & & & & $\mathrm{K}(1 / 1) \mathrm{M}(1 / 1) \mathrm{O}(1 / 1)$ \\
\hline & 149 & 7 & 11 & 9 & 10 & 4 & 30 & 8 & $\mathrm{~L}(1 / 1)$ \\
\hline \multirow[t]{3}{*}{50} & 50 & 14 & 10 & 20 & 19 & 8 & 3 & 20 & $\mathrm{D}(1 / 2)$ \\
\hline & 146 & 14 & 10 & 20 & 19 & 8 & 29 & 20 & $\mathrm{C}(1 / 3)$ \\
\hline & 150 & 14 & 10 & 20 & 19 & 8 & 3 & 53 & $\mathrm{~N}(1 / 1)$ \\
\hline \multirow[t]{2}{*}{74} & 74 & 22 & 13 & 8 & 29 & 8 & 3 & 31 & $\mathrm{~A}(2 / 6) \mathrm{B}(1 / 7) \mathrm{H}(1 / 1)$ \\
\hline & 148 & 22 & 13 & 46 & 29 & 8 & 3 & 31 & $\mathrm{I}(1 / 1)$ \\
\hline
\end{tabular}


Fig. 1

Dendogram derived from the Unweighted Pair Group Method with Arithmetic Average (UPGMA) used for cluster analyses using the DICE similarity coefficient and a band-matching index greater than $0.8 \%$ among the PFGE profiles of all isolates of $P$. multocida obtained from porcine bronchopneumonia. Clusters (A-O) was determined by $50 \%$ similarity between profiles. 


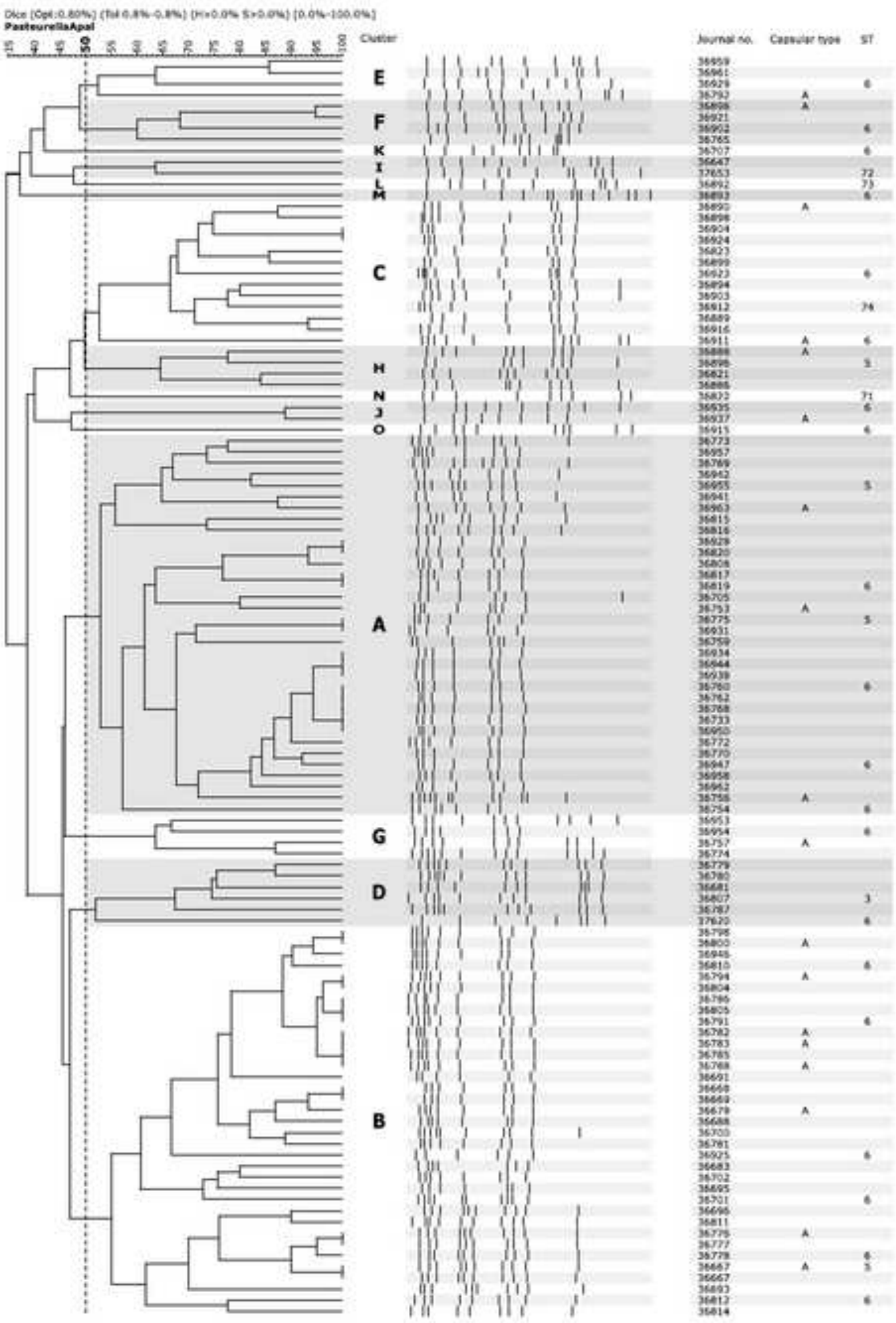

